Brit. J. vener. Dis. (1961), 37, 170.

\title{
NON-GONOCOCCAL VAGINITIS*
}

BY

\author{
MARIO CARDIA \\ Oporto, Portugal
}

I propose to deal with certain aspects of nongonococcal vaginitis based on work carried out at the Central Clinic for Social Health at Oporto, of which I am the director.

The Clinic, which is under the direction of the Ministry of Health, occupies three buildings in Oporto, a town of 300,000 inhabitants in a province of $1,300,000$ inhabitants, and its work extends to the suburban areas. The turnover of patients (all ambulant) is very large: in 1959 the number of consultations and treatments in the four departments of Dermatology, Gynaecology, Ophthalmology, and Stomatology totalled 313,514 (a daily average of 1,114$)$.

Male cases of venereal disease attend the dermatological clinic and female cases the gynaecological clinic.

The chief aim of the whole organization is prophylactic, and to this end a Social Science Service has been set up to undertake epidemiological studies and to bring the carriers of disease to the clinic for treatment and cure. Reservoirs of infection are sought out so that suspected cases and contacts may be examined and treated, particular attention being paid to public and clandestine prostitutes, who are given frequent medical examinations and are encouraged to give up their trade.

Treatment is nearly always free, especially that given for preventive reasons.

In the 4 years $1954-58,10,547$ new patients were treated in the gynaecological clinic (apart from a treatment centre reserved for prostitutes) and 4,202 were found to be infected with V.D. (572 were seropositive, 485 had gonorrhoea, 71 had soft chancre, 2 had Nicholas Favre's disease, and 3,072 had trichomoniasis).

* Paper read at the European Symposium of the I.U.V.D.T. at Cracow, Poland, in September, 1960.
Special notice is taken of infectious and parasitic vaginitis, our aim being to let no case of gonorrhoea escape diagnosis.

\section{Trichomoniasis}

Incidence.-The Central Dispensary at Oporto was the first in the country to examine all its female patients for $T$. vaginalis. For some little time we have used microscopic investigation only in cases with vaginal discharge, vaginal inflammation, or greenishyellow leucorrhoea and pruritus. The number of cases discovered has remained about the same ( 20 to 30 per cent.) and this is also the proportion of cases discovered in the course of medical examinations of prostitutes. At the V.D. Symposium held at Washington in 1956, I reported that in 1955 the percentage of cases of trichomoniasis in prostitutes was 47.6 per cent., but by 1957 I was able to report to the Rheims Symposium that this number had already fallen to $25-30$ per cent.

I propose to confine myself to certain new aspects which seem to deserve consideration and which are based on my own observations.

Therapy.-We have tried various local treatments, especially vaginal suppositories, aerosol sprays, and dusting with aureomycin. The immediate results are usually good; the discharge and irritation are relieved and the trichomonads disappear, but relapse is very frequent. We have also tried oral treatment. Trithéon has proved the only really effective drug, and is useful in males where local treatment is difficult. Three $100 \mathrm{mg}$. tablets can be given daily for 7 to 15 days and so far the cures have been maintained for 8 to 10 months. This drug can be used for both man and wife. 
Post-Operative Infection.-A point which I have not seen made by any other worker is that, in certain cases of hysterectomy, patients who had no trichomonal infestation pre-operatively developed a heavy discharge after resuming marital intercourse, and this was shown by the microscope to be due to $T$. vaginalis. This contradicts the unanimous conclusions of the Rheims Symposium in 1957 regarding the venereal origin of trichomoniasis.

\section{Vaginal Fungus}

Other interesting infestations are those caused by the mycoses, which are widespread in Portugal, though less common than the trichomonad. They rarely cause such serious cases of disease as are seen, e.g. in Brazil. We usually treat them with gentian violet suppositories which give better results than those recorded by other authors for other remedies, and are less often followed by relapse.

\section{Other Causes of Discharge}

Besides the gonococcus, the trichomonad, and fungi, which are the most frequent causes of heavy greenish-yellow leucorrhoea, there are various other conditions which cause discomfort to the patient.

The cervix should be carefully examined. The use of the colposcope may avoid unnecessary microscopic cultures and may show where a biopsy should be taken. Benign lesions can then be safely treated by electro-coagulation, though this is not advisable if malignancy is suspected.

Senile vaginitis (both menopausal or following surgical intervention) may also cause a discharge. The vagina and cervix show characteristic appearances of white atrophied mucous membrane specked with red. The lugol test will show up the white areas where glycogen is absent, and colposcopy enables an exact diagnosis to be made. Vaginitis due to diminution of folliculin is cured or improved by local and systemic oestrogens.

\section{Conclusions}

Apart from the gonococcal infections, those cited above are the most common causes of vaginitis. Rarely the discharge may be due to tuberculosis, syphilis, or some other bacterial agency. B. coli does not seem to me to be an important cause.

Vaginitis, both gonococcal and otherwise, deserves close attention. Apart from other genital complications, the presence of a discharge requires that the practitioner should make an accurate diagnosis. Very many women come to the gynaecological clinic complaining of a discharge (often with painful micturition, vulval irritation, and dyspareunia). No treatment should be given in such cases without careful examination. Vaginitis is a most serious question, social and psychological as well as medical. The patients are often distressed by conjugal and mental worries, and the practitioner may need to call in the assistance of the social worker to help solve their problems.

\section{Summary}

Gonorrhoea is still widespread in many countries, but the principal object of the present paper has been to discuss the aetiology of vaginal discharge. Apart from that due to cancer, pre-cancer, or gonorrhoea, the possible causes include trichomonads, mycoses, oestrogen insufficiency, epithelial changes in the vagina and cervix, syphilis, tuberculosis, and a variety of bacteria.

\section{Vaginites non-gonococciques Résumé}

La blénnorragie est encore répandue dans plusieurs pays, mais le problème qui nous intéresse en ce moment est celui de l'étiologie des leucorrhées pathologiques, non comprises les maladies cancéreuses, pré-cancéreuses, et blénnorragiques. Parmi les causes les plus importantes il faut prendre note des suivantes: trichomonases, micoses, insuffisance oestrogénique, altération de l'épithélium cervical et vaginal, syphilis, tuberculose et autres agents microbiens. 